Abdalla Saad Abdalla Al-Zawi ${ }^{1}$, Mohammed Omer ${ }^{2}$, Elizabeth Tan ${ }^{3}$, Beata Adamczyk ${ }^{4}$, Jessica English ${ }^{5}$, Mohamed Elamass ${ }^{3}$, Soad Eldruki ${ }^{6}$ (D)

${ }^{1}$ Breast Unit, Basildon \& Thurrock University Hospital, Basildon, Essex, United Kingdom

2Department of Histopathology, Addenbrooke's Hospital, Cambridge, United Kingdom

${ }^{3}$ Departmet of Surgery, Basildon \& Thurrock University Hospital, Basildon, Essex, United Kingdom

${ }^{4}$ Greater Poland Cancer Centre, Poznan, Poland

${ }^{5}$ Department of Radiology, Basildon \& Thurrock University Hospital, Basildon, Essex, United Kingdom

${ }^{6}$ Department of Pathomorphology, Benghazi Medical Centre, Benghazi, Libyan Arab Jamahiriya

\title{
Human Epidermal Growth Factor-2 Receptor [HER2] Status in Patients Aged 70 years or more with Operable Early Breast Cancer - Multicentre Based Study with Review of 150 Cases
}

\section{Corresponding author:}

Abdalla Saad Abdalla Al-Zawi Breast Unit, Basildon \& Thurrock University Hospital, Nether Mayne, SS16 5NL Basildon, Essex United Kingdom

e-mail: abdalasaad@gmail.com

Medical Research Journal 2019; Volume 4, Number 3, 157-162 10.5603/MRJ.a2019.0031 Copyright $\odot 2019$ Via Medica ISSN 2451-2591

\begin{abstract}
Background: Breast cancer is the most common invasive cancer in females but often has more favourable tumour biology in the older age group. More than $30 \%$ of those diagnosed with breast cancer worldwide are aged $\geq 65$. Some report this percentage to be even higher, reaching up to more than $50 \%$ in developed countries that have a longer overall life expectancy.

Within this group, hormone receptor-positive and human epidermal growth factor-2 (HER-2) negative are the most favourable tumour biological patterns. In contrast, the triple-negative breast cancer group has the worst prognosis. Invasive breast cancers in younger age groups have a more poorly differentiated histological grade, more hormone receptor-negative status, a remarkable extent of lympho-vascular invasion and a greater expression/amplification of HER-2 than older age groups. HER-2 receptor is amplified and over-expressed in about $20-30 \%$ of invasive breast cancers within all age groups.

To analyse the status of HER-2 receptors early invasive breast cancer in relation to the histological subtype in the older age group.

Methods: The study group includes 150 patients with early breast cancer. The patho-morphological data and immune-histochemistry results of invasive cancer have been analysed, this included histology subtype, grade, oestrogen/progesterone receptor status as well as HER-2 expression.

Results: HER-2 expression was only seen in 17\% of cases, it was seen mainly in Grade 3 cancers (9\%), followed by Grade $2(6 \%)$, with Grade 1 cancer accounting for only $1 \%$ of the study group.

Conclusions: Patients with breast cancer aged $\geq 70$ are seen to have less aggressive biology and expression of HER-2 receptors.
\end{abstract}

Key words: breast cancer, HER-2 receptor, trastuzumab

Med Res J 2019; 4 (3): 157-162

\section{Introduction}

Breast cancer is the most common cancer among females, accounting for one-third of female cancers, and is the second leading cancerous cause of death in women after lung cancer [1]. The risk of developing breast cancer in a woman aged $\geq 70$ is much higher than in women aged below 70 years.
The estimated risk reaches $3.82 \%$ ( 1 in 26 women) at the age of 70 , almost more than twice the risk of a 40 -year old woman (1.47\% or 1 in 62 women) [2].

HER-2 is a receptor for epidermal growth factor which stimulates different intracellular signal transduction pathways related to cell growth and differentiation control. HER-2 overexpression is detected in $20-30 \%$ of diagnosed invasive breast cancers and this is associat- 

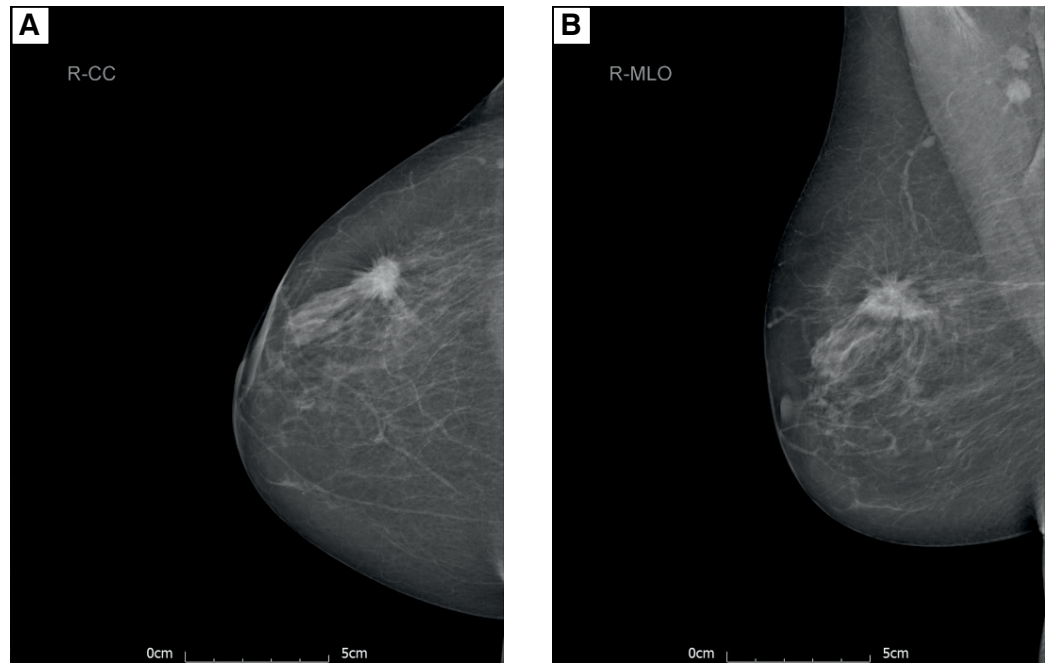

Figure 1. A - Mammogram - CC view; B — Mammogram — MLO view; Right mammogram — Spiculated mass lesion right $U O Q$ measuring approximately $31 \times 20 \times 19 \mathrm{~mm}$. Appearances are highly suspicious for malignancy. Prominent lymph nodes seen in the axilla, suspicious of metastatic disease

ed with aggressive tumour features, poor prognosis and an unfavourable outcome [3]. The aim of this paper is to analyse the status of HER-2 receptors early invasive breast cancer in relation to the histological subtype in the older age group.

\section{Methods}

\section{Patients}

A database of 150 patients aged $\geq 70$ with early operable primary breast cancer has been analysed. The preoperative diagnosis was through triple assessment, including mammogram (Fig. 1) and histopathology. These patients had been managed at Basildon University Hospital (Essex-England) and Greater Poland Oncology Centre (Poznan, Poland). The treatment period was from 2011 to 2016 . The patient information has been identified from the electronic records including demographic, clinical and histopathological details.

\section{Immuno-histochemical analysis}

The immuno-histochemical studies were performed by the local team in each hospital using local diagnostic techniques. Quick score (Q-Score) technique was used at Basildon University Hospital to examine oestrogen and progesterone receptor status. The final scores ranged between $0-8$, where 0 was negative and 8 strongly positive. At the Poznan centre, oestrogen and progesterone receptor status was performed using immune-histochemistry on the core biopsy. If the histochemical score (H score) was $50 \%$ or more, the outcome was a positive result.

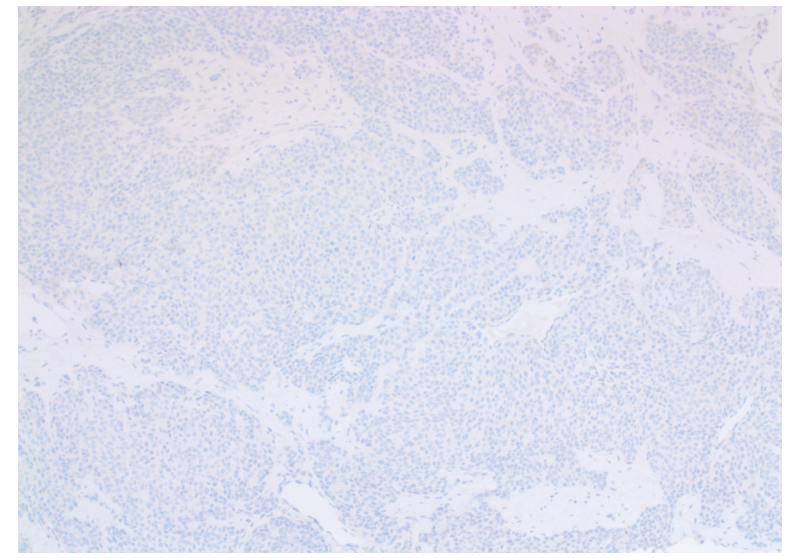

Figure 2. HER-2 negative invasive breast cancer

The technique to measure HER-2 protein uses an antibody which probes for HER-2 in tumour cells. Score (0) or $(1+)$ were reported as negative (Fig. 2) and (3+) as positive [Figure 3]. The result was reported as borderline if the score was (2+). FISH test (Fluorescence In-Situ Hybridization) was used to measure HER-2 gene amplification in the tumour cells of borderline cases. When FISH score was $\geq 2$, the result was regarded as positive.

\section{Results}

The group was composed of 150 patients with an age range of $70-88$ and a median age of 76 . Grade 2 cancer was the most common among this group (53\% of cases), followed by Grade 3 (23\%) and Grade $1(21 \%)$ (Tab. 1). HER-2 expression was only seen in 
$17 \%$ of cases $(n=25)$ (Fig. 4). HER-2 positive was seen mainly in Grade 3 cancers (9\%), followed by Grade 2 (6\%), with Grade 1 cancer accounting for only $1 \%$ of the study group (Fig. 5). Triple negative cancer was detected in just $10 \%$ (Tab. 1, Fig. 6).

\section{Discussion}

HER-2 is a cell membrane protein receptor mediated by the transmission of signals controlling normal cell growth and differentiation. In general, the number of existing HER-2 cell membrane receptors in normal cells is small (Fig. 7). When the number of HER-2 receptors is high, the cell signalling is stronger (Fig. 8), leading to amplified responsiveness to epidermal growth factors and carcinogenesis [4].

It has been reported that the incidence of breast carcinoma increases with age, with approximately $30 \%$ of new breast carcinoma cases being diagnosed in patients $\geq 70$ [5]. Breast cancer in advanced age has different biological features and clinical behaviour. For example, elderly breast cancer often expresses remarkable positivity for oestrogen receptor (ER), lower histopathological grade, and HER-2 negative tumours [6-10]. The younger age groups tend to

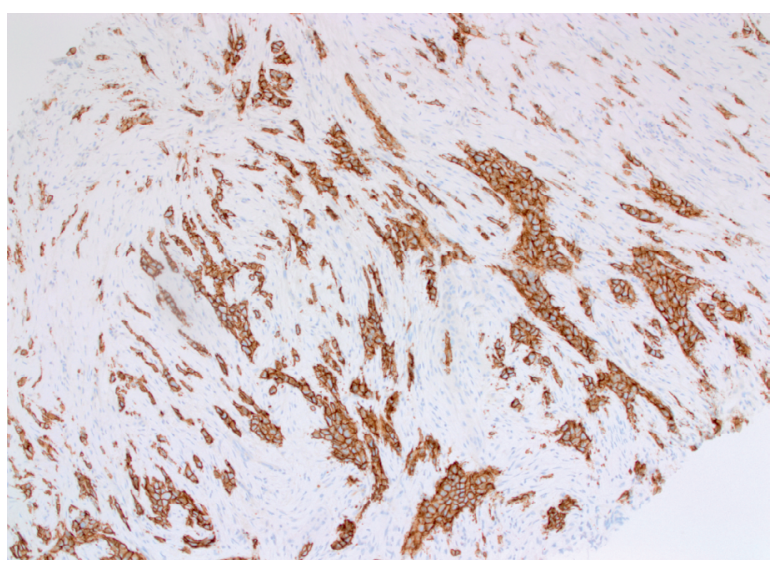

Figure 3. HER-2 positive invasive breast cancer have a more poorly differentiated histological grade, more hormone receptor negative status, a remarkable extent of lympho-vascular invasion and greater expression/amplification of HER-2. However, there is also data which reports that breast cancer is more aggressive in the elderly.

In 2008, Durbecq et al analysed the effect of ageing on the incidence of breast cancer molecular subtypes in 2723 breast cancer cases. The results showed almost $19 \%$ of older women had luminal B tumours. This group is more likely to present with a higher histopathological grade, larger tumour size, and increased predisposition to lymph node metastasis, despite being hormone receptor positive [11]. Recent studies indicate that the percentage of HER-2 positive cases amongst the older age group with breast cancer accounted for $10 \%$ to $20 \%$, which is similar to the figures reported in the entire breast cancer population [12]. The data also suggests that tumour specific features should be used to assess the risk of relapse and to plan management. The age progression itself is associated with changes in biological breast structure and physiology, such as increased sensitivity to oestrogen hormone, epithelial

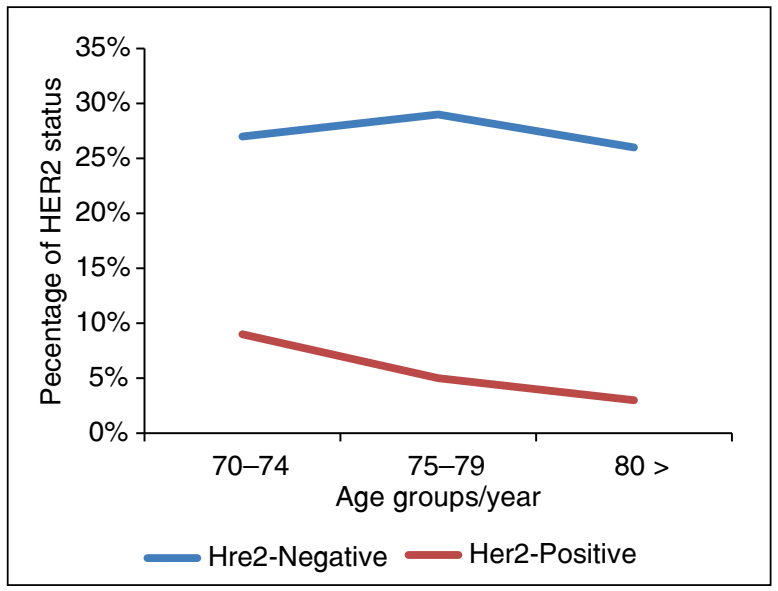

Figure 4. HER-2 status distribution pattern status in 150 breast cancer patients aged $\geq 70$, operated on for early breast cancer

Table 1. HER-2 status in 150 breast cancer patients aged $\geq 70$, operated on for early breast cancer

\begin{tabular}{|c|c|c|c|c|c|}
\hline & Age & Grade I & Grade II & Grade III & Total \\
\hline \multirow[b]{2}{*}{ HER2 - Negative } & $70-74$ & $9(6 \%)$ & $25(17 \%)$ & $7(5 \%)$ & $41(27 \%)$ \\
\hline & $75-79$ & $12(8 \%)$ & $24(16 \%)$ & $8(5 \%)$ & 44 (29\%) \\
\hline \multirow{4}{*}{ HER2 — Positive } & $80>$ & $9(6 \%)$ & $21(14 \%)$ & $10(6 \%)$ & $40(26 \%)$ \\
\hline & $70-74$ & $2(1 \%)$ & $5(3 \%)$ & $6(4 \%)$ & $13(9 \%)$ \\
\hline & $75-79$ & 0 & $3(2 \%)$ & $4(3 \%)$ & 7 (5\%) \\
\hline & $80>$ & 0 & $2(1 \%)$ & $3(2 \%)$ & $5(3 \%)$ \\
\hline Total & & $32(21 \%)$ & $80(53 \%)$ & $38(25 \%)$ & 150 (100\%) \\
\hline
\end{tabular}




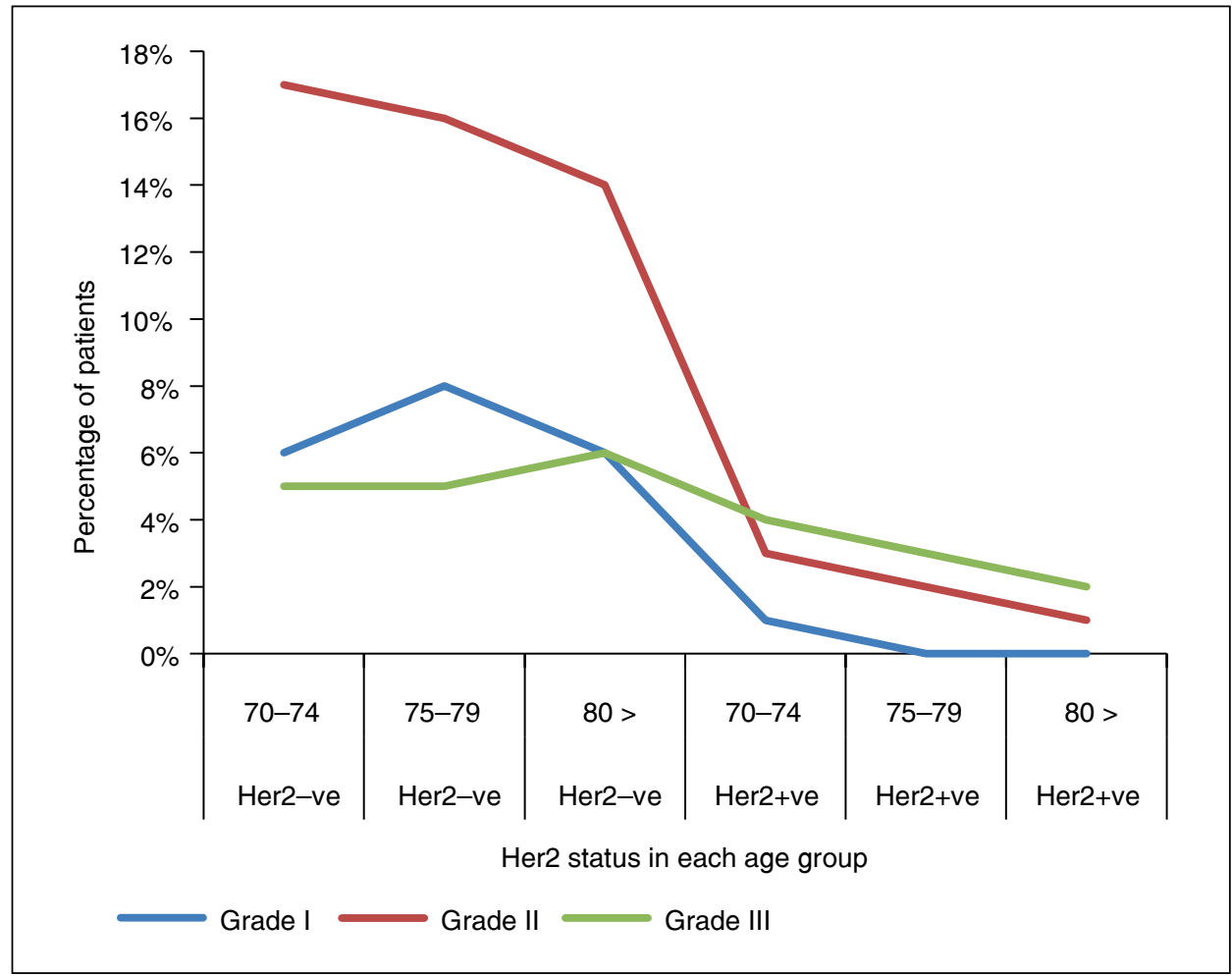

Figure 5. HER-2 receptor status in different tumour grades in 150 breast cancer patients aged $\geq 70$, operated on for early breast cancer

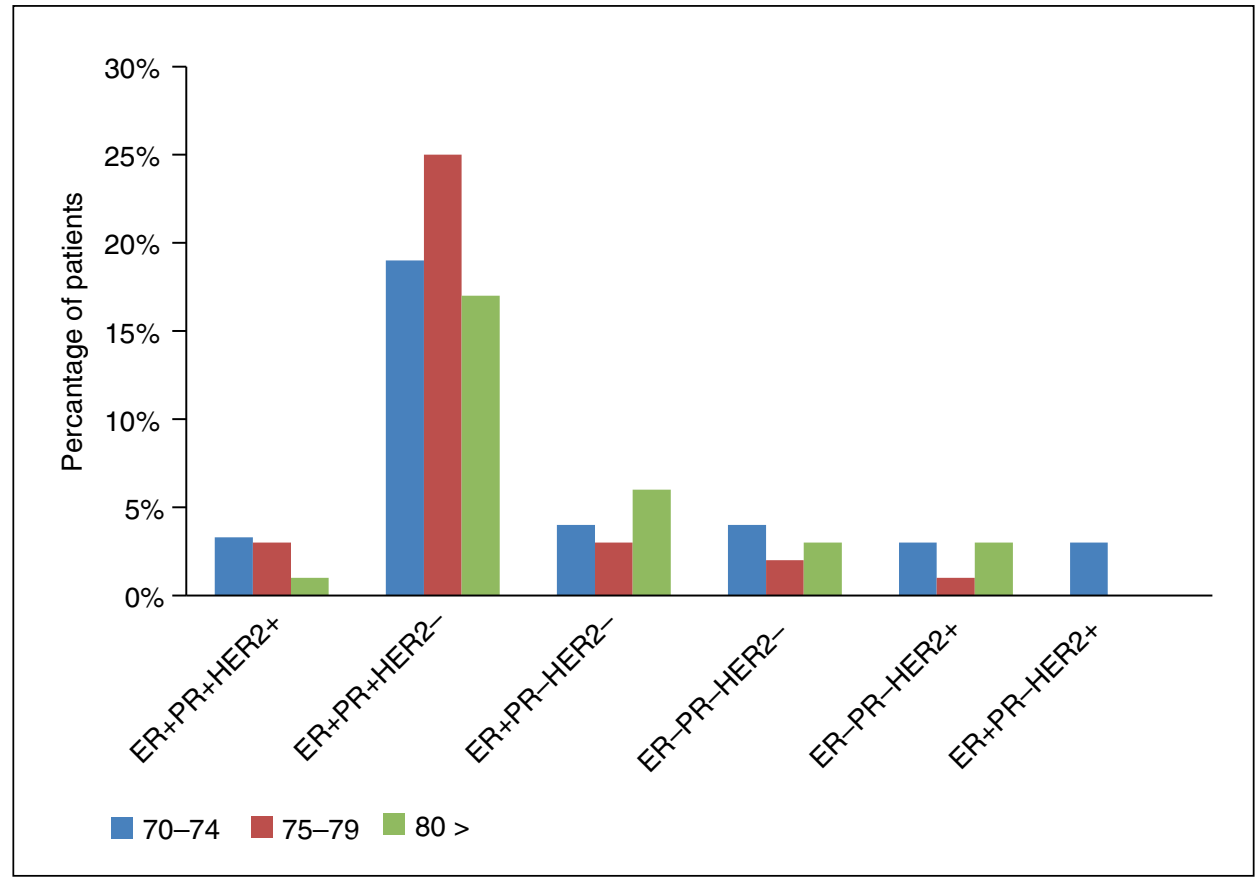

Figure 6. Receptor status in 150 breast cancer patients aged $\geq 70$, operated on for early breast cancer; ER - Oestrogen Receptor; PR - Progesterone Receptor; HER2 — Human Epidermal Growth Factor-2 Receptor 


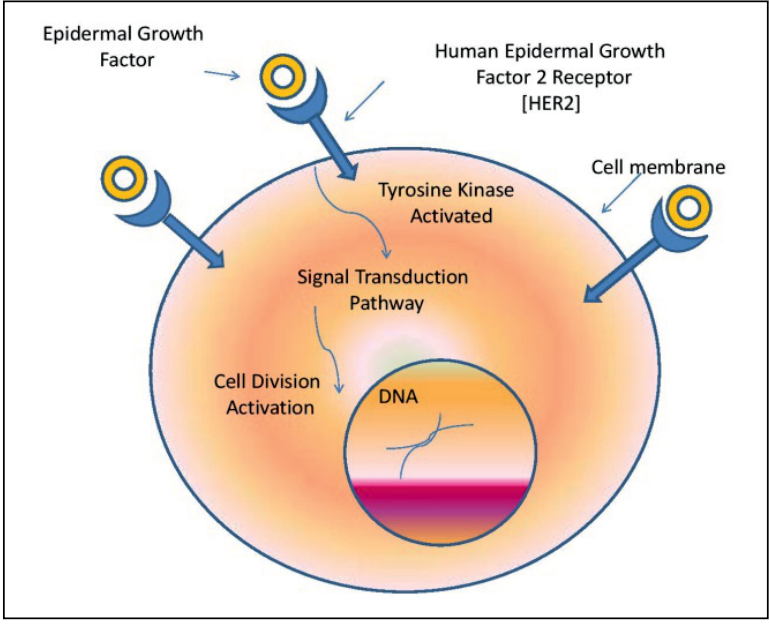

Figure 7. The normal number of Human Epidermal Growth Factor-2 Receptor (HER-2) in the cell

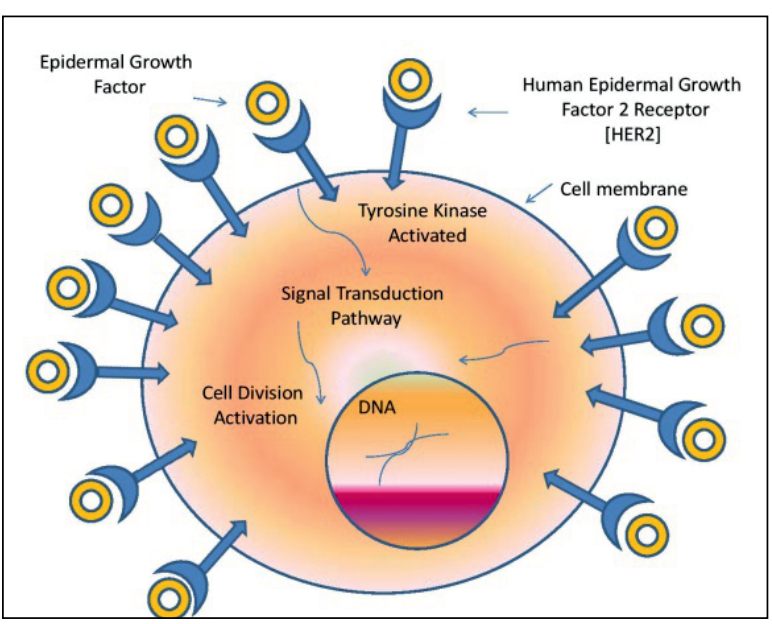

Figure 8. Over expression rate of Human Epidermal Growth Factor-2 Receptor (HER-2)

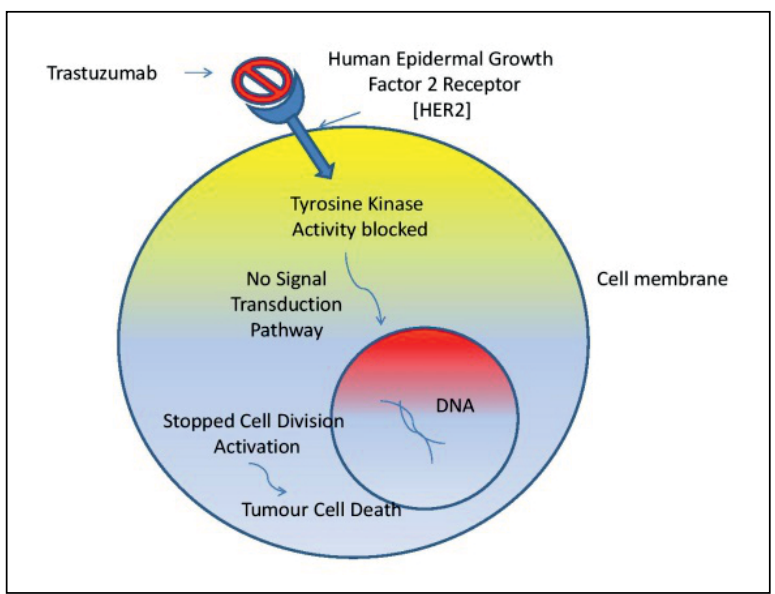

Figure 9. The monoclonal antibody Trastuzumab acting by blocking HER-2 receptors cell alterations, immune senescence, and tumour microenvironment modifications. All of these factors could be related to an increased incidence of breast cancer and associated mortality [13].

A positive aspect of the disease is that many diagnosed breast cancer cases are at an early stage (non-metastatic), and can be classified as a potentially curable disease. Since the 1990s, the monoclonal antibody trastuzumab has greatly changed the treatment pattern and prognosis of human epidermal growth factor receptor-2 (HER-2) positive breast cancer. The trastuzumab attaches to the HER-2 receptor and prevents the human epidermal growth factor from attaching to the same site. This prevents cell proliferation and initiates tumour cell death (Fig. 9). Many HER-2 positive breast cancer patients have a good response to trastuzumab-based systemic therapy. This has been reported in long-term follow-up observations, where the overall survival in this patient group has improved by $37 \%$ [14-18].

When breast cancer systemic therapy was introduced, it did not have the same impact on the older age group as in younger age groups [12, 19-20]. The reason for this may have been that systemic therapy was less frequently given to the older age group, as the breast cancer was often less aggressive and showed positive expression for oestrogen hormone receptor and negative expression for human epidermal growth factor receptor-2 (HER-2). There were also concerns about toxicity related to adjuvant chemotherapy and trastuzumab use [21]. However, it is now agreed that age should not be the main driver in decision making for cancer therapy in the older age group; this is based on recent reports and observations [14, 22]. A holistic assessment for individual patient physiological reserve and quality of life following the intervention are needed to offer the most appropriate management option.

The mortality associated with older age group breast cancer can be explained by under-treatment, late diagnosis, and insufficient individual screening. Fit elderly breast cancer patients should be given a fair chance and offered treatment in the same way as their younger counterparts.

\section{Conclusion}

In conclusion, patients with breast cancer aged $\geq 70$ are seen to have less aggressive biology and expression of HER-2 receptors. With the ageing population, there is an increase in the number of diagnosed women with breast cancer aged $\geq 70$ years; treatment in this characteristic age group should be individualised to the tumour specific biological features and patient related factors. Elderly breast cancer patients should 
be given the equal opportunity to be offered treatment in the same way as their younger counterparts.

\section{Acknowledgement}

\author{
Many thanks to Ms Sarah COLQUHOUN, Senior \\ Library Assistant at Basildon Healthcare Library at Basil- \\ don University Hospital, for her assistance in gathering \\ the reference papers.
}

\section{References}

1. DeSantis C, Ma J, Bryan L, et al. Breast cancer statistics, 2013. CA Cancer J Clin 2014: 64(1): 52-62, doi: 10.3322/caac. 21203, indexed in Pubmed: 24114568

2. National Cancer Institute: Breast cancer risk in American women http://www.cancer.gov/cancertopics/types/breast/risk-fact-shee (19.11.2017)

3. Baselga J, Albanell J. Mechanism of action of anti-HER2 monoclona antibodies. Ann Oncol. 2001; 12 Suppl 1: S35-S41, doi: 10.1093/annonc/12.suppl 1.s35, indexed in Pubmed: 11521720

4. Rubin I, Yarden Y. The basic biology of HER2. Ann Oncol. 2001; 12 Suppl 1: S3-S8, doi: 10.1093/annonc/12.suppl 1.s3, indexed in Pubmed: 11521719

5. Orucevic A, Curzon M, Curzon C, et al. Breast Cancer in Elderly Caucasian Women-An Institution-Based Study of Correlation between Breast Cancer Prognostic Markers, TNM Stage, and Overall Survival. Cancers (Basel). 2015; 7(3): 1472-1483, doi: 10.3390/cancers7030846, indexed in Pubmed: 26264027.

6. Aapro M, Wildiers $\mathrm{H}$. Triple-negative breast cancer in the older population. Ann Oncol. 2012; 23 Suppl 6: vi52-vi55, doi: 10.1093/annonc/mds189, indexed in Pubmed: 23012304

7. Daidone MG, Coradini D, Martelli G, et al. Primary breast cancer in elderly women: biological profile and relation with clinical outcome. Crit Rev Oncol Hematol. 2003; 45(3): 313-325, indexed in Pubmed: 12633842

8. Diab SG, Elledge RM, Clark GM. Tumor characteristics and clinica outcome of elderly women with breast cancer. J Natl Cancer Inst. 2000; 92(7): 550-556, doi: 10.1093/jnci/92.7.550, indexed in Pubmed: 10749910.

9. Molino A, Giovannini M, Auriemma A, et al. Pathological, biological and clinical characteristics, and surgical management, of elderly women with breast cancer. Crit Rev Oncol Hematol. 2006; 59(3): 226-233, doi: 10.1016/j.critrevonc.2006.01.007, indexed in Pubmed: 16533603.

10. Clark GM, Osborne CK, McGuire WL. Correlations between estrogen receptor, progesterone receptor, and patient characteristics in human breast cancer. J Clin Oncol. 1984; 2(10): 1102-1109, doi: 10.1200/JCO.1984.2.10.1102, indexed in Pubmed: 6491696

11. Durbecq V, Ameye L, Veys I, et al. A significant proportion of elderly patients develop hormone-dependant "luminal-B" tumours associated with aggressive characteristics. Crit Rev Oncol Hematol. 2008; 67(1): 80-92, doi: 10.1016/j.critrevonc.2007.12.008, indexed in Pubmed: 18313937.

12. Freedman RA, Muss HB. Managing metastatic human epidermal growth factor receptor 2 (HER2)-positive breast cancer in the older patient. J Geriatr Oncol. 2014; 5(1): 2-7, doi: 10.1016/j.jgo.2013.10.001, indexed in Pubmed: 24484711.

13. Lodi M, Scheer L, Reix N, et al. Breast cancer in elderly women and altered clinico-pathological characteristics: a systematic review. Breast Cancer Res Treat. 2017; 166(3): 657-668, doi: 10.1007/s10549-0174448-5, indexed in Pubmed: 28803352.

14. Slamon D, Eiermann W, Robert N, et al. Breast Cancer International Research Group. Adjuvant trastuzumab in HER2-positive breast cancer. N Engl J Med. 2011; 365(14): 1273-1283, doi: 10.1056/NEJMoa0910383, indexed in Pubmed: 21991949

15. Romond E, Perez E, Bryant J, et al. Trastuzumab plus Adjuvant Chemotherapy for Operable HER2-Positive Breast Cancer. N Engl J Med. 2005; 353(16): 1673-1684, doi: 10.1056/nejmoa052122.

16. Leyland-Jones B, Arnold A, Gelmon K et al. Pharmacologic insights into the future of trastuzumab. Ann Oncol. 2001; 12 Suppl 1: S43-S47, doi: 10.1093/annonc/12.suppl_1.s43, indexed in Pubmed: 11521721.

17. Baselga J. Phase I and II clinical trials of trastuzumab. Annals of Oncology. 2001; 12(suppl 1): S49-S55, doi: 10.1093/annonc/12.suppl 1.s49.

18. Perez EA, Romond EH, Suman VJ, et al. Trastuzumab plus ājuvant chemotherapy for human epidermal growth factor receptor 2-positive breast cancer: planned joint analysis of overall survival from NSABP B-31 and NCCTG N9831. J Clin Oncol. 2014; 32(33): 3744-3752, doi: 10.1200/JCO.2014.55.5730, indexed in Pubmed: 25332249.

19. Muss HB. Adjuvant chemotherapy in older women with breast cancer: who and what? J Clin Oncol. 2014; 32(19): 1996-2000, doi: 10.1200/JCO.2013.54.8586, indexed in Pubmed: 24868030.

20. Dall P, Lenzen G, Göhler T, et al. Trastuzumab in the treatment of elderly patients with early breast cancer: Results from an observational study in Germany. J Geriatr Oncol. 2015; 6(6): 462-469, doi: 10.1016/j. go.2015.06.003, indexed in Pubmed: 26341962

21. Denegri A, Moccetti T, Moccetti M, et al. Cardiac toxicity of trastuzumab in elderly patients with breast cancer. J Geriatr Cardiol. 2016; 13(4): 355-363, doi: 10.11909/j.issn.1671-5411.2016.04.003, indexed in Pubmed: 27403145

22. Sun J, Chia S. Adjuvant chemotherapy and HER-2-directed therapy for early-stage breast cancer in the elderly. Br J Cancer. 2017; 116(1): 4-9, doi: 10.1038/bjc.2016.360, indexed in Pubmed: 27875517. 